\title{
Kajian Perencanaan Tebal Perkerasan Jalan Nasional Poros Bua - Rantepao
}

\author{
Ayukardona*1, Rais Rachman*2, Louise Elizabeth Radjawane*3 \\ *1 Mahasiswa Program Studi Teknik Sipil, Universitas Kristen Indonesia Paulus Makassar, \\ Indonesia ayhu2810@gmail.com \\ *2,3 Dosen Program Studi Teknik Sipil, Universitas Kristen Indonesia Paulus Makassar, Indonesia \\ $\underline{\text { rais.rachman@gmail.com }}^{* 2}$ dan eliz_louise@yahoo.com ${ }^{* 3}$
}

Corresponding Author: ayhu2810@gmail.com

\begin{abstract}
Abstrak
Penelitian ini dilakukan untuk mendesain ulang tebal perkerasan lentur jalan Bua - Rantepao dengan menggunakan metode Manual Desain Perkerasan Jalan 2013 yang ditetapkan dari pihak Kementerian Pekerjaan Umum Direktorat Jenderal Bina Marga tahun 2013. Percepatan peningkatan Jalan Bua Rantepao dilakukan karena terdapat banyak kendaraan berat yang melintas menyebabkan kontruksi lebih mudah mengalami kerusakan dan adanya objek wisata yang menjadi pemicu terjadinya kenaikan level kemacetan lalu lintas. Pengumpulan data berupa data primer tentang kondisi lalu lintas pada Jalan Bua - Rantepao serta data LHR dan data sekunder berupa data $C B R$. Berdasarkan hasil penelitian dari perencanaan tebal perkerasan menggunakan metode Manual Desain Perkerasan Jalan 2013 diperoleh hasil tebal perkerasan desain 3 dengan lapis permukaan $A C$ - $W C$ setebal $40 \mathrm{~mm}, A C$ $B C$ setebal $155 \mathrm{~mm}$, lapis pondasi atas memakai $C T B$ setebal $150 \mathrm{~mm}$ dan lapis pondasi bawah memakai LPA kelas A setebal $150 \mathrm{~mm}$. Bilamana $C T B$ tidak dapat diterapkan atau sumber daya tidak memadai diolah, untuk itu jalan keluarnya memakai desain $3 \mathrm{~A}$ yaitu lapis permukaan $A C$ - $W C$ setebal $40 \mathrm{~mm}$, lapis $A C-B C$ setebal $60 \mathrm{~mm}$ dan $A C$-Base setebal $80 \mathrm{~mm}$. Tebal lapis pondasi bawah LPA kelas A dengan setebal $300 \mathrm{~mm}$. Metode efektif yang dapat digunakan adalah metode Bina Marga 2013 desain 3A lapis permukaan $A C$ - $W C$ setebal $40 \mathrm{~mm}$, lapis $A C$ - $B C$ setebal $60 \mathrm{~mm}$ dan $A C$-Base setebal $80 \mathrm{~mm}$. Tebal lapis pondasi bawah LPA kelas A setebal $300 \mathrm{~mm}$.
\end{abstract}

Kata kunci: Metode Bina Marga 2013, Tebal Perkerasan Lentur, Peningkatan Ruas Jalan BuaRantepao.

\footnotetext{
Abstract

This research was conducted to redesign the flexible pavement thickness of the Bua-Rantepao road using the Road Pavement Design Manual method 2013 set by the Ministry of Public Works, Directorate General of Bina Marga in 2013. The acceleration of the improvement of Jalan Bua Rantepao is carried out because there are many heavy vehicles that pass, causing the building to be more easily damaged and the presence of tourist objects that trigger the level of traffic congestion. The data collection was in the form of primary data on traffic conditions on Jalan Bua-Rantepao and $A D T$ and secondary data in the form of CBR data. Based on the results of the research on pavement thickness planning using the Road Pavement Design Manual method 2013, the results obtained are design 3 pavement thicknesses with a surface layer of $40 \mathrm{~mm}$ thick $A C$-WC, $155 \mathrm{~mm}$ thick $A C-B C$, the top foundation layer using $150 \mathrm{~mm}$ thick CTB and the lower foundation layer using LPA class A with a thickness of $150 \mathrm{~mm}$. If the CTB is difficult to implement or there are insufficient resources to do it, the solution is to use the $3 A$ design, namely the AC-WC surface layer with a thickness of $40 \mathrm{~mm}$, an
} 
$A C$-BC layer with a thickness of $60 \mathrm{~mm}$ and an AC-Base layer with a thickness of $80 \mathrm{~mm}$. The thickness of the LPA class A sub-base layer is $300 \mathrm{~mm}$ thick. The effective method that can be used is the 2013 Bina Marga method, design 3A, $40 \mathrm{~mm}$ thick AC-WC surface layer, $60 \mathrm{~mm}$ thick AC-BC layer and $80 \mathrm{~mm}$ thick AC-Base. The thickness of the LPA class A sub-base layer is $300 \mathrm{~mm}$ thick.

Keywords: Bina Marga Method 2013, Flexible Pavement Thickness, Improvement of the BuaRantepao Road Section.

\section{PENDAHULUAN}

Sarana jalan adalah salah satu aspek angkutan darat yang dimaksudkan demi kelancaran mobilitas orang dan barang. Menurut Undang - Undang Nomor 38 Tahun 2004 Jalan mempunyai peran penting dalam peningkatan bidang ekonomi, sosial dan budaya serta lingkungan melalui pertumbuhan suatu wilayah untuk mewujudkan pembangunan nasional yang meluas dan merata [1].

Kelancaran lalu-lintas banyak bergantung pada kondisi perkerasan jalan. Apabila permukaan jalan mengalami kerusakan, lalu-lintas akan terganggu. Usaha-usaha perlu dilakukan agar jaringan jalan selalu dalam kondisi lancar dari segi pelayanan.

Akses jalan di Kabupaten Toraja tidak semuanya memiliki permukaan jalan yang baik. Salah satu ruas yang mendapat perhatian yaitu Jalan Bua - Rantepao. Jalan yang menghubungkan dua kota kabupaten ini yaitu Toraja Utara dan Luwu sebelum adanya pembangunan jalan ini, aksesibilitas terdekat masyarakat dari Rantepao menuju ke Bua yaitu melalui jalan poros Sa'dan-Palopo dengan waktu tempuh 3 jam. Untuk meningkatkan waktu tempuh, maka pembangunan Jalan Bua-Rantepao dilakukan.

Pada penelitian ini akan dilakukan analisis tentang tebal perkerasan jalan yang dibutuhkan pada Jalan Bua Rantepao pada segmen 1 STA 00+000 sampai dengan STA 2+350 untuk umur rencana jalan (UR) 20 tahun dengan menggunakan perkerasan lentur metode Manual Desain Perkerasan (MDP) 2013 [2].

Kontruksi jalan lama atau yang disebut dengan eksisting didefinisikan sebagai Laston $A C$-WC dengan lebar rata-rata 3,50 m menjadi 7,00 m. Dulunya jalan ini adalah jalan kolektor dan dikelompokkan menjadi jenis jalan dengan tipe dua-lajur satu-arah (2/1 UD). Berdasarkan statusnya jalan tersebut adalah jalan provinsi.

Percepatan peningkatan Jalan Bua - Rantepao dikarenakan terdapat banyak kendaraan berat yang melintas menyebabkan kontruksi yang lebih mudah mengalami kerusakan dan adanya objek wisata yang menjadi pemicu terjadinya kenaikan level kemacetan lalu lintas pada daerah ini, melalui hal tersebut pula dibutuhkan adanya suatu pembahasan mengenai tebal lapisan perkerasan pada lokasi Jalan Bua - Rantepao, sehingga nantinya struktur jalan yang dihasilkan dapat menopang beban suatu lalu lintas yang semakin meningkat.

Beberapa penelitian sejenis terdahulu dengan hasilnya, yaitu Perencanaan Tebal Perkerasan Lentur Jalan Raya Antara Bina Marga Dan Aashto'93 menghasilkan perbandingan tebal perkerasan dengan menerapkan metode Bina Mrga: Lapis permukaan yaitu laston MS-744 kg setebal $50 \mathrm{~mm}$, Lapis pondasi yaitu Batu Pecah CBR 100\% Setebal $200 \mathrm{~mm}$ dan Lapisan pondasi bawah yaitu Batu Pecah CBR 50\% setebal $90 \mathrm{~mm}$. sedangkan untuk tebal perkerasan dengan menerapkan metode AASHTO: Lapis permukaan yaitu laston MS$744 \mathrm{~kg}$ setebal $75 \mathrm{~mm}$, Lapis pondasi yaitu Batu Pecah CBR 100\% Setebal $200 \mathrm{~mm}$; dan Lapis pondasi bawah yaitu Batu Pecah CBR 70\% + Agregat Sub Base setebal 390 mm [3], Peningkatan Jalan Dengan Menggunakan Perkerasan Lentur Ruas Jalan Beru-Cinandang (Sta 0+000 - 3+000) Kecamatan Dawar Blandong Kabupaten Mojokerto menghasilkan perencanaan geometrik jalan untuk badan jalan selebar $7 \mathrm{~m}$, perencanaan tebal perkerasan digunakan Laston setebal $160 \mathrm{~mm}$ dan overlay setebal $160 \mathrm{~mm}$, pondasi atas berupa batu pecah kelas A setebal $200 \mathrm{~mm}$, lapis pondasi bawah sirtu kelas A setebal $100 \mathrm{~mm}$ dan desain 
drainase pasangan batu kali dengan ukuran $\mathrm{b}=50 \mathrm{~cm}, \mathrm{~h}=70 \mathrm{~cm}, \mathrm{w}=30 \mathrm{~cm}$ serta perhitungan rencana biaya senilai Rp. 11,397,729,919 [4], Analisis Desain Perkerasan Jalan Metode Bina Marga 1987, Bina Marga 2002 Dan Evaluasi Struktur Perkerasan Jalan (Ruas Pelebaran Jalan Bantal - Mukomuko Bengkulu) (WINRIP Paket 11) menghasilkan perkerasan jalan pada paket pelebaran jalan dengan menerapkan metode Bina Marga 1987 yaitu: $A C$ - $W C$ dengan tinggi $40 \mathrm{~mm}, A C$ - $B C$ dengan tinggi $60 \mathrm{~mm}, A C$-Base dengan tinggi $75 \mathrm{~mm}$, Agregat Base Kelas A dengan tinggi $150 \mathrm{~mm}$, Agregat Base Kelas B dengan tinggi $200 \mathrm{~mm}$ dan Urugan Pilihan dengan tinggi $300 \mathrm{~mm}$. Sedangkan untuk tebal perkerasan dengan menerapkan metode Bina Marga 2002 yaitu: $A C$ - $W C$ dengan tinggi $375 \mathrm{~mm}, A C$ - $B C$ dengan tinggi $50 \mathrm{~mm}, A C$-Base dengan tinggi 75 $\mathrm{mm}$, Agregat Base Kelas A dengan tinggi $150 \mathrm{~mm}$, Agregat Base Kelas B dengan tinggi $200 \mathrm{~mm}$ dan Urugan Pilihan dengan tinggi $300 \mathrm{~mm}$. Serta desain tebal perkerasan pada paket pelebaran jalan sesuai PPJN Bengkulu yang diterapkan di lokasi yaitu: $A C$ - $W C$ setebal $50 \mathrm{~mm} ; A C-B C$ setebal $60 \mathrm{~mm}$; $A C$-Base setebal 75 mm; Agregat Base Kelas A setebal 150 mm; Agregat Base Kelas B setebal 200 mm dan Urugan Pilihan setebal 300 mm [5], Perencanaan Tebal Perkerasan Lentur Dengan Metode AASHTO 1993 Dan MDP Jalan 2013 pada Ruas Jalan Pirime - Balingga Kabupaten Lanny Jaya (Sta 0+000 S/D Sta 7+500) menghasilkan tebal perkerasan lentur dengan menerapkan metode Manual Desain Perkerasan (MDP) tahun 2013 di dapatkan lapis permukaan setebal $100 \mathrm{~mm}$, lapis pondasi atas tidak tercantum dalam tabel dan lapis pondasi bawah setebal $400 \mathrm{~mm}$. Sedangkan tebal perkerasan lentur dengan menerapkan metode AASHTO 1993 lapis permukaan setebal $50 \mathrm{~mm}$, lapis pondasi atas setebal $100 \mathrm{~mm}$ dan lapis pondasi bawah setebal $220 \mathrm{~mm}$. Penentuan tebal lapis perkerasan, mengingat keefektifan dari segi biaya Manual Desain Perkerasan (MDP) 2013 membutuhkan biaya pelaksanaan senilai Rp.157.005.580.000,00 dan AASHTO 1993 membutuhkan biaya pelaksanaan senilai Rp.113.687.971.000,00. Maka secara efisien dan efektif perencanaan tebal lapisan perkerasan diterapkan metode AASHTO 1993 dan dilaksanakan selama 7 bulan atau 168 hari kalender [6], Perbandingan Tebal Perkerasan Lentur Metode Analisa Komponen Dan AASHTO (Studi Kasus: Jalan Lubuk Alai - Koto Lamo Kabupaten Lima Puluh Kota menghasilkan untuk umur rencana 10 tahun dengan menerapkan metode Analisa Komponen lapis permukaan yaitu Laston Ms 340 setebal 50 mm, lapis pondasi atas yaitu Batu Pecah Kelas A setebal $150 \mathrm{~mm}$ dan lapis pondasi bawah yaitu Sirtu Kelas B setebal $100 \mathrm{~mm}$. sedangkan untuk tebal perkerasan dengan menerapkan metode AASHTO 1993 lapis permukaan yaitu Laston Ms 340 setebal 110 mm, lapis pondasi atas yaitu Batu Pecah Kelas A setebal 80 mm dan lapis pondasi bawah yaitu Sirtu Kelas B setebal $180 \mathrm{~mm}$ [7], Perencanaan Tebal Perkerasan Lentur dan Anggaran Biaya Di Jalan Pare-Kediri Kota Kediri menghasilkan struktur perkerasan umur rencana 20 tahun lapis pondasi bawah yaitu batu pecah B setebal $250 \mathrm{~mm}$, untuk lapis pondasi atas yaitu batu pecah kelas A setebal $200 \mathrm{~mm}$, dan lapisan permukaan yaitu Laston ACMS 744 setebal $70 \mathrm{~mm}$, sedangkan nilai biaya yang diperlukan senilai Rp. 21.253.066.282,48 [8], Analisis Perencanaan Tebal Perkerasan Lentur Jalan Dengan Menggunakan Metode Analisa Komponen Bina Marga 1987 pada Ruas Jalan Banjaran-Balamoa menghasilkan tebal perkerasan jalan lapis permukaan yaitu Laston MS $744 \mathrm{~kg}$ setebal paling kecil $50 \mathrm{~mm}$, lapis pondasi atas yaitu Laston Atas MS $590 \mathrm{~kg}$ setebal $100 \mathrm{~mm}$ dan lapis pondasi bawah yaitu Sirtu/Pitrun Kelas B setebal $50 \mathrm{~mm}$ [9], Analisis Perencanaan Tebal Perkerasan Lentur Dengan Metode Bina Marga (Studi Kasus: Jalan Luar Lingkar Timur Surabaya) menghasilkan lapis permukaan menerapkan metode Bina Marga yaitu: Lapis pondasi bawah memakai Agregat Kelas B (CBR 80\%) setebal $200 \mathrm{~mm}$, Lapis pondasi atas memakai Agregat Kelas A (CBR 95\%) setebal $150 \mathrm{~mm}$, dan Lapis permukaan memakai $A C-W C$ setebal $50 \mathrm{~mm}$ dan $A C-B C$ setebal $200 \mathrm{~mm}[10]$. 


\section{METODOLOGI}

\section{Gambaran Umum dan Lokasi Penelitian}

Lokasi yang dijadikan untuk penelitian perencanaan tebal perkerasan jalan dilakukan pada ruas Jalan Bua Rantepao Jl. Ke'te Kesu', Toraja Utara, tepatnya pada STA 00+000 sampai dengan STA 2+350 dengan kondisi medan perbukitan.

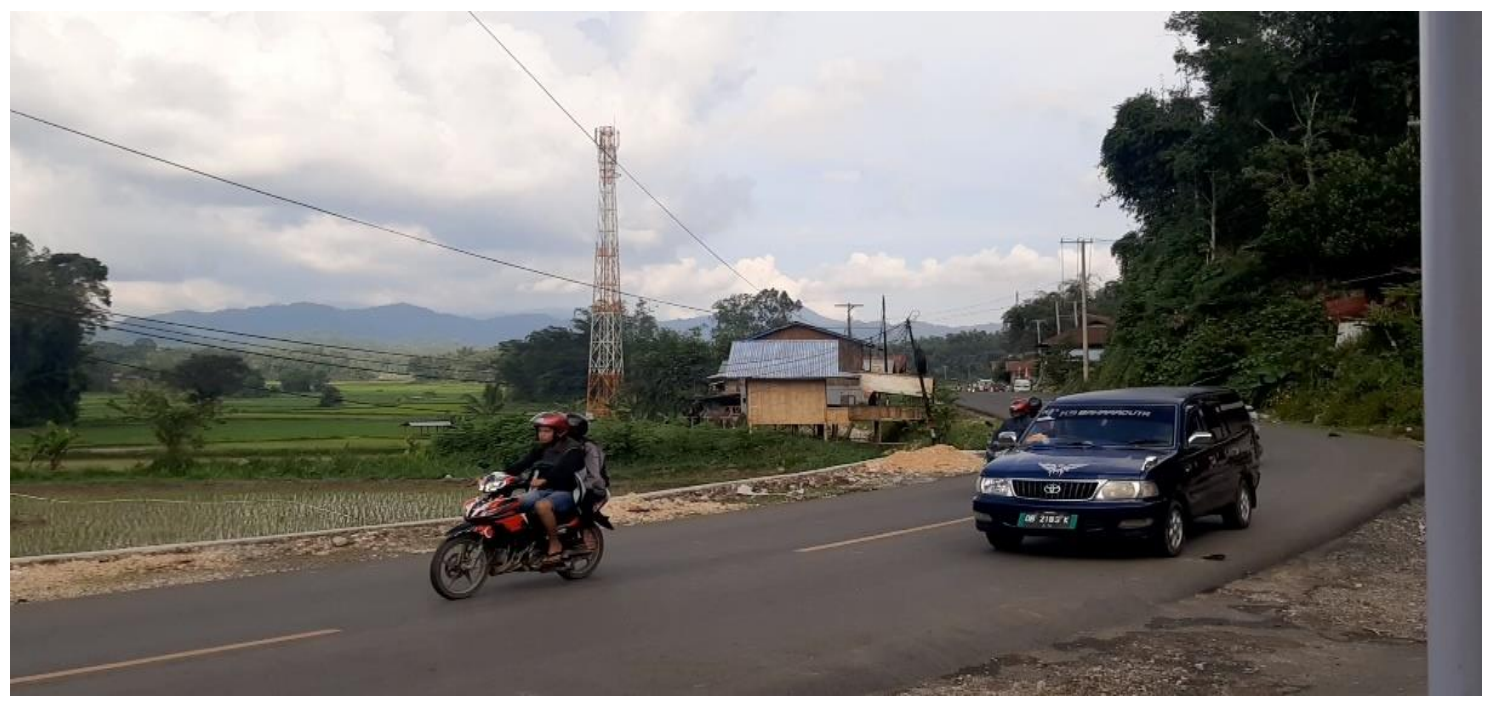

Gambar 1. Kondisi Lalu Lintas di Lapangan

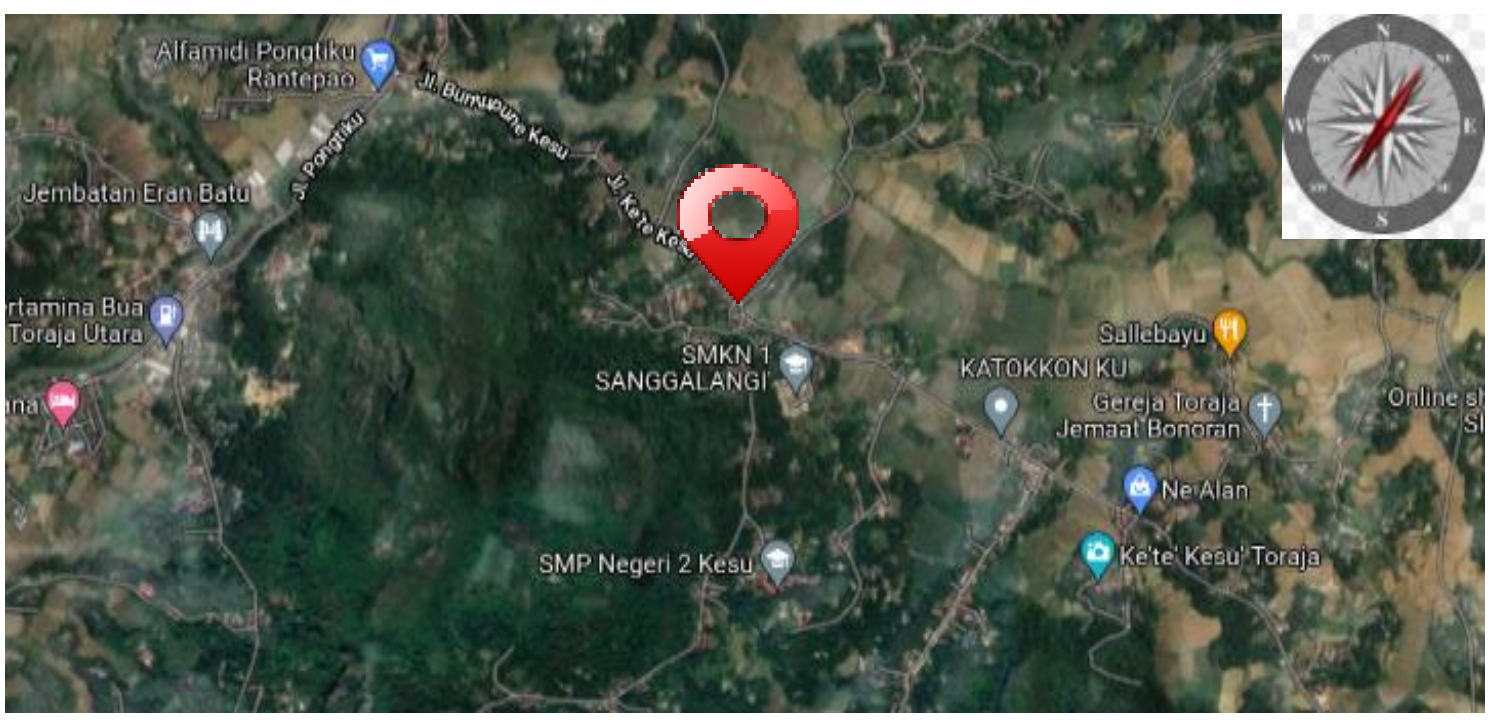

Gambar 2. Lokasi Penelitian

\section{Pengumpulan Data}

Memahami terlebih dahulu metode penelitian lalu menyiapkan kebutuhan data yang akan digunakan. Pada penelitian ini data yang dibutuhkan berupa data primer dan data sekunder. Data primer merupakan pengamatan yang dilakukan secara langsung dengan cara mengamati distribusi lalu lintas di lokasi penelitian untuk mendapatkan nilai LHR, sedangkan data sekunder merupakan data pendukung yang didapatkan dari penelitian sebelumnya bersumber pada instansi-instansi terkait dari jalan yang ditinjau, yaitu data $C B R$. 


\section{Pengolahan Data}

Adapun pengolahan data dilakukan dengan menghitung lalu lintas harian rata-rata (LHR) pada STA $1+150$ kemudian menentukan umur rencana perkerasan yaitu 20 tahun, setelah mengetahui nilai LHR maka selanjutnya menghitung ESA (Lintas Sumbu Standar Ekivalen) kendaraan niaga dan menghitung CESA sesuai umur rencana. Setelah mengetahui nilai ESA dan CESA maka dapat ditentukan desain pondasi jalan dan pilihan jenis perkerasan yang akan digunakan kemudian menentukan desain tebal perkerasan.

\section{HASIL DAN PEMBAHASAN}

Adapun data lalu lintas Ruas Jalan Bua - Rantepao yang akan direncanakan tebal perkerasannya ditunjukkan pada Tabel 1 sebagai berikut.

Tabel 1. Data Lalu Lintas Ruas Jalan Bua - Rantepao

\begin{tabular}{|c|c|c|}
\hline No. & Data & Keterangan \\
\hline 1 & Jenis Jalan & Arteri Primer \\
\hline 2 & Umur Rencana (UR) & 20 tahun (2021-2041) \\
\hline 3 & Pertumbuhan lalu lintas (i) & $4 \%$ \\
\hline 4 & Distribusi Kendaraan & 2 Jalur, 2 Arah (2/2 UD) \\
\hline
\end{tabular}

\section{Analisis Lalu Lintas}

Informasi pengelompokan kendaraan pada Ruas Jalan Bua - Rantepao ditunjukkan pada Tabel 2.

Tabel 2. Data Lalu Lintas Rata-rata Ruas Jalan Bua - Rantepao

\begin{tabular}{ccc}
\hline No. & Jenis Kendaraan & $\begin{array}{c}\text { LHR } \\
\text { (Kend/2 Arah/Hari) }\end{array}$ \\
\hline 1 & $\begin{array}{c}\text { Mobil Penumpang, Angkutan Umum, } \\
\text { Pick-Up, dll. (Gol. 1, 2, 3 \& 4) }\end{array}$ & 4393 \\
\hline 2 & Bus Kecil Gol. 5a & 2 \\
\hline 3 & Bus Besar Gol. 5b & 1 \\
\hline 4 & Truk 2 gandar sedang Gol. 6a & 161 \\
\hline 5 & Truk 2 gandar besar Gol. 6b & 110 \\
\hline 6 & Truk 3 gandar Gol. 7a1 & - \\
\hline 7 & Truk 3 gandar Gol. 7b & 2 \\
\hline 8 & Truk 3 gandar Gol. 7c & - \\
\hline
\end{tabular}

Dari data di atas maka akan didapat nilai sebagai berikut.

a. Faktor pertumbuhan lalu lintas

Faktor pertumbuhan lalu lintas ditetapkan pada persentase tahunan (\%/tahun). Melalui penerapan rumus pada Persamaan 1, persentasi peningkatan pertumbuhan lalu lintas pada umur 20 tahun yakni mencapai angka $29,778 \%$. 
b. Rencana jumlah kendaraan dalam periode 20 tahun

1) Faktor distribusi lajur untuk kendaraan niaga ditunjukkan pada Tabel 3. Beban rencana tiap lajur tidak diperbolehkan melebihi kapasitas lajur pada tiap tahun selama umur rencana.

Tabel 3. Faktor Distribusi Lajur (DL)

\begin{tabular}{cc}
\hline $\begin{array}{c}\text { Jumlah Lajur Setiap } \\
\text { Arah }\end{array}$ & $\begin{array}{c}\text { Kendaraan niaga pada lajur desain } \\
\text { (\% terhadap populasi kendaraan niaga) }\end{array}$ \\
\hline 1 & 100 \\
\hline 2 & 80 \\
\hline 3 & 60 \\
\hline 4 & 50 \\
\hline
\end{tabular}

2) Jenis kendaraan mempunyai angka ekivalen atau Vehicle Damage Factor (VDF) yaitu akumulasi angka ekivalen sumbu depan dan angka ekivalen sumbu belakang.

3) Nilai Traffic Multiplier (TM) pada keadaan pembebanan berlebih di Indonesia yakni mencapai1,8 2. nilai TM 1,8 digunakan untuk desain.

4) Cumulative Equivalent Single Axle Load (CESA) adalah nilai total kumulatif muatan sumbu lalu lintas pada lajur desain selama jangka waktu yang diharapkan.

Oleh karena itu, evaluasi total keseluruhan jumlah kendaraan yang direncanakan selama periode 20 tahun dapat dilihat pada Tabel 4 .

Tabel 4. Prediksi Jumlah Kendaraan Selama Umur Rencana

\begin{tabular}{|c|c|c|c|c|c|c|c|c|}
\hline \multicolumn{2}{|c|}{ Jenis Kendaraan } & \multirow{2}{*}{$\begin{array}{c}\boldsymbol{V D F} \\
0\end{array}$} & \multirow{2}{*}{$\begin{array}{l}\mathbf{D}_{\mathbf{l}} \\
0,8\end{array}$} & \multirow{2}{*}{$\begin{array}{c}\begin{array}{c}\text { LHR/ } \\
\text { hari }\end{array} \\
4.393\end{array}$} & \multirow{2}{*}{$\begin{array}{c}E S A \\
0\end{array}$} & \multirow{2}{*}{$\begin{array}{c}\mathbf{R} \\
29,778\end{array}$} & \multirow{2}{*}{$\begin{array}{c}\mathrm{CESA}_{4} \\
0\end{array}$} & \multirow{2}{*}{$\begin{array}{c}\mathrm{CESA}_{5} \\
0\end{array}$} \\
\hline $\begin{array}{c}\text { Gol } \\
1,2, \\
3,4\end{array}$ & $\begin{array}{c}\text { Mobil } \\
\text { penumpang }\end{array}$ & & & & & & & \\
\hline Gol 5a & Bus kecil & 0,3 & 0,8 & 2 & 0,6 & 29,778 & $5.217,11$ & $9.390,79$ \\
\hline Gol 5b & Bus besar & 1 & 0,8 & 1 & 1 & 29,778 & $8.695,18$ & $15.651,32$ \\
\hline $\begin{array}{l}\text { Gol } \\
\text { 6a.2 }\end{array}$ & $\begin{array}{c}\text { Truk } 2 \text { gandar } \\
\text { sedang }\end{array}$ & 0,8 & 0,8 & 161 & 128,8 & 29,778 & $1.119 .938,67$ & $2.015 .889,60$ \\
\hline $\begin{array}{c}\text { Gol } \\
6 \mathrm{~b} 1.2\end{array}$ & $\begin{array}{c}\text { Truk } 2 \text { gandar } \\
\text { besar }\end{array}$ & 1,6 & 0,8 & 110 & 176 & 29,778 & $1.530 .350,98$ & $2.754 .631,76$ \\
\hline Gol 7a1 & Truk 3 gandar & 7,6 & 0,8 & 0 & 0 & 29,778 & 0,00 & 0,00 \\
\hline Gol 7b & Truk 3 gandar & 36,9 & 0,8 & 0 & 0 & 29,778 & 0,00 & 0,00 \\
\hline Gol 7c & Truk 3 gandar & 13,6 & 0,8 & 2 & 27,2 & 29,778 & $236.508,79$ & $425.715,82$ \\
\hline & & & $A 20$ & & & & $2.900 .710,714$ & $5.221 .279,284$ \\
\hline
\end{tabular}




\section{Desain Pondasi Jalan}

Tabel 5. Bagan Desain 2: Solusi Desain Pondasi Jalan Minimum Yang Digunakan

\begin{tabular}{|c|c|c|c|c|c|c|}
\hline \multirow[t]{3}{*}{$\begin{array}{l}\text { CBR Tanah } \\
\text { Dasar }\end{array}$} & \multirow[t]{3}{*}{$\begin{array}{l}\text { Kelas Kekuatan } \\
\text { Tanah Dasar }\end{array}$} & \multirow[t]{3}{*}{$\begin{array}{c}\text { Prosedur } \\
\text { desain } \\
\text { pondasi }\end{array}$} & \multirow[t]{3}{*}{$\begin{array}{l}\text { Deskripsi struktur } \\
\text { pondasi jalan }\end{array}$} & \multicolumn{3}{|c|}{$\begin{array}{c}\text { lalu lintas lajur desain } \\
\text { umur rencana } 40 \\
\text { tahun } \\
\text { (juta CESA })\end{array}$} \\
\hline & & & & $<2$ & $2-4$ & $>4$ \\
\hline & & & & \multicolumn{3}{|c|}{$\begin{array}{c}\text { Tebal minimum } \\
\text { neningkatan tanah dasar }\end{array}$} \\
\hline$\geq 6$ & SG6 & A & $\begin{array}{l}\text { Perbaikan tanah dasar } \\
\text { meliputi bahan }\end{array}$ & \multicolumn{3}{|c|}{$\begin{array}{l}\text { Tidak perlu } \\
\text { peningkatan }\end{array}$} \\
\hline 5 & SG5 & & \multirow{4}{*}{$\begin{array}{l}\text { stabilisasi kapur atau } \\
\text { timbunan pilihan } \\
\text { (pemadatan berlapis } \\
\leq 200 \text { mm tebal lepas) }\end{array}$} & & & 100 \\
\hline 4 & SG4 & & & 100 & 150 & 200 \\
\hline 3 & SG3 & & & 150 & 200 & 300 \\
\hline 2.5 & SG2.5 & & & 175 & 250 & 350 \\
\hline \multicolumn{2}{|c|}{ Tanah ekspansif (potential swell> 5\%) } & $\mathrm{AE}$ & & 400 & 500 & 600 \\
\hline \multirow{2}{*}{\multicolumn{2}{|c|}{$\begin{array}{ll}\text { Perkerasan } & \text { SG1 } \text { aluvial }^{1} \\
\text { lentur diatas } \\
\text { tanah lunak }\end{array}$}} & \multirow{2}{*}{ B } & 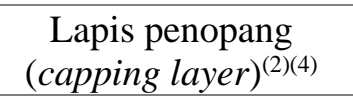 & 1000 & 1100 & 1200 \\
\hline & & & $\begin{array}{l}\text { Atau lapis penopang } \\
\text { dan geogrid }\end{array}$ & 650 & 750 & 850 \\
\hline \multicolumn{2}{|c|}{$\begin{array}{l}\text { Tanah gambut dengan HRS atau } \\
\text { perkerasan Burda untuk jalan kecil (nilai } \\
\text { minimum - peraturan lain digunakan) }\end{array}$} & $\mathrm{D}$ & $\begin{array}{l}\text { Lapis penopang } \\
\text { berbutir }^{(2)(4)}\end{array}$ & $\begin{array}{c}100 \\
0\end{array}$ & $\begin{array}{l}12 \\
50\end{array}$ & 1500 \\
\hline
\end{tabular}

CBR Tanah Dasar $=28,793 \%$. Bagan desain solusi pondasi jalan yaitu level ketahanan tanah dasar: SG6; Struktur desain pondasi: A, tidak diperlukan peningkatan tanah dasar.

\section{Pemilihan Jenis Lapis Perkerasan}

Pemilihan jenis perkerasan ditunjukkan melalui nilai ESA 20 tahun (juta) yang dapat dilihat pada Tabel 4 di bab sebelumnya. Sehingga didapatkan jenis perkerasan yang digunakan diperoleh dari nilai CESA 20 tahun sebesar 2.900.710,714 adalah dengan struktur perkerasan $A C$ atau $H R S$ tipis diatas lapis pondasi berbutir dan dengan menggunakan Desain 3. berikut adalah rincian pemilihan jenis perkerasan yang digunakan dari Manual Desain Perkerasan 2013pada Tabel 6.

Tabel 6. Pemilihan Jenis Perkerasan yang Digunakan

\begin{tabular}{|c|c|c|c|c|c|c|}
\hline \multirow[t]{2}{*}{ Struktur Perkerasan } & \multirow[t]{2}{*}{ Desain } & \multicolumn{5}{|c|}{$\begin{array}{c}E S A 20 \text { tahun (juta) } \\
\text { (pangkat } 4 \text { kecuali disebutkan lain) }\end{array}$} \\
\hline & & $0-0.5$ & $0.1-4$ & $4-10$ & $10-30$ & $>30$ \\
\hline Perkerasan kaku dengan lalu lintas berat & 4 & & & 2 & 2 & 2 \\
\hline $\begin{array}{l}\text { Perkerasan kaku dengan lalu lintas rendah } \\
\text { (desa dan daerah perkotaan) }\end{array}$ & $4 \mathrm{~A}$ & & 1.2 & & & \\
\hline $\begin{array}{c}A C W C \text { modifikasi atau } \\
\text { SMA modifikasi dengan } C T B \text { (pangkat 5) }\end{array}$ & 3 & & & & 2 & \\
\hline$A C$ dengan $C T B$ (pangkat5) & 3 & & & 2 & & \\
\hline $\begin{array}{c}A C \text { tebal } \geq 100 \mathrm{~mm} \text { dengan lapis pondasi } \\
\text { berbutir (pangkat } 5 \text { ) }\end{array}$ & $3 \mathrm{~A}$ & & & 1.2 & & \\
\hline $\begin{array}{c}A C \text { atau } H R S \text { tipis diatas lapis pondasi } \\
\text { berbutir }\end{array}$ & 3 & & 1.2 & & & \\
\hline
\end{tabular}




\begin{tabular}{clll}
$\begin{array}{c}\text { Burda atau Burtu dengan LPA kelas A atau } \\
\text { bantuan asli }\end{array}$ & 6 & 3 & 3 \\
\hline
\end{tabular}

Maka, dari parameter yang sudah didapatkan CESA4 0,1 - 4 juta ESA, Pemilihan jenis perkerasan yang digunakan adalah bagan desain 3 perkerasan lentur.

Tebal lapis perkerasan lentur diperoleh dari nilai CESA 5 sebesar 5.221.279,28 ESAL. Berikut adalah tebal tiap lapis perkerasan yang dapat dilihat pada Tabel 18 sesuai dengan Bagan Desain 3 dari Manual Desain Perkerasan 2013.

Tabel 7. Bagan Desain 3: Desain Perkerasan Lentur opsi biaya minimum termasuk CTB) Yang Digunakan

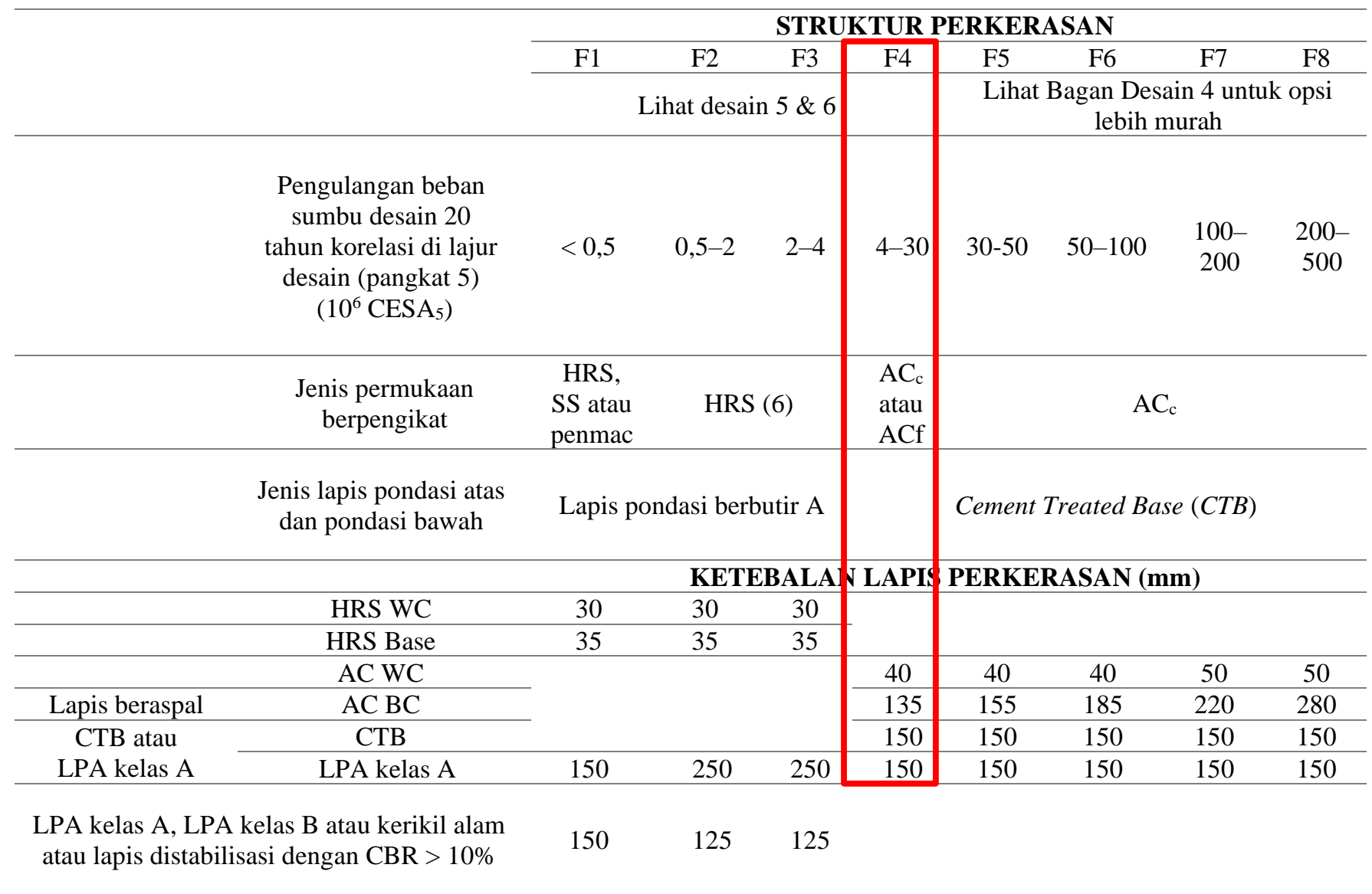

Tabel 8. Bagan Desain 3A: Desain Perkerasan Lentur - Aspal dengan Lapis Pondasi Berbutir Yang Digunakan

\begin{tabular}{|c|c|c|c|c|c|c|c|c|c|}
\hline & & \multicolumn{5}{|c|}{ STRUKTUR PERKERASAN } & & & \\
\hline & FF1 & FF2 & FF3 & FF4 & FF5 & FF6 & FF7 & FF8 & FF9 \\
\hline \multicolumn{3}{|c|}{\begin{tabular}{|l} 
Solusi yang dipilih \\
\end{tabular}} & & & \multicolumn{2}{|c|}{ Lihat Catatan 3} & \multicolumn{3}{|c|}{ Lihat Catatan 3} \\
\hline $\begin{array}{c}\text { Pengulangan beban sumbu } \\
\text { desain } 20 \\
\text { tahun di lajur rencana } \\
\text { (pangkat 5) } \\
\left(10^{6} \mathrm{CESA}_{5}\right)\end{array}$ & $1-2$ & $2-4$ & $4-7$ & $\begin{array}{l}7- \\
10\end{array}$ & $\begin{array}{c}10- \\
20\end{array}$ & $20-30$ & $\begin{array}{c}30- \\
50\end{array}$ & $\begin{array}{l}50- \\
100\end{array}$ & $\begin{array}{c}100 \\
- \\
200\end{array}$ \\
\hline \multicolumn{10}{|c|}{ KETEBALAN LAPIS PERKERASAN (mm) } \\
\hline $\mathrm{AC} \mathrm{WC}$ & 40 & 40 & 40 & 40 & 40 & 40 & 40 & 40 & 40 \\
\hline $\mathrm{AC}$ binder & 60 & 60 & 60 & 60 & 60 & 60 & 60 & 60 & 60 \\
\hline AC Base & 0 & 70 & 80 & 105 & 145 & 160 & 180 & 210 & 245 \\
\hline LPA & 400 & 300 & 300 & 300 & 300 & 300 & 300 & 300 & 300 \\
\hline
\end{tabular}




\begin{tabular}{l|l|l|l|l|l|l|l|l|l|} 
Catatan & 1 & 1 & 2 & 2 & 3 & 3 & 3 & 3 & 3 \\
\hline
\end{tabular}

Catatan: FF3 akan lebih efektif biaya relatif terhadap solusi F4 pada kondisi tertentu

Oleh karena itu, pada Desain 3 nilai CESA 5 masuk ke dalam kelompok struktur perkerasan F4 dan Bagan Desain 3A Nilai CESA 5 masuk ke dalam kelompok struktur perkerasan FF3, Sehingga diperoleh tebal perkerasan:

Desain 3:

Lapis permukaan $A C$ - $W C$ setebal $40 \mathrm{~mm}, A C-B C$ setebal $155 \mathrm{~mm}$, lapis pondasi atas memakai $C T B$ setebal $150 \mathrm{~mm}$ dan lapis pondasi bawah memakai LPA kelas A setebal $150 \mathrm{~mm}$ sehingga total keseluruhan $475 \mathrm{~mm}$.

Desain 3A (yang digunakan):

tebal lapis permukaan $A C$ - $W C$ setebal $40 \mathrm{~mm}$, lapis $A C$ - $B C$ setebal $60 \mathrm{~mm}$ dan $A C$-Base setebal $80 \mathrm{~mm}$. Tebal lapis pondasi bawah LPA kelas A setebal $300 \mathrm{~mm}$ sehingga total keseluruhan $480 \mathrm{~mm}$.

Tabel 9. Perbandingan Metode Bina Marga 2013 dengan Desain Sebelumnya

\begin{tabular}{cccc}
\hline $\begin{array}{c}\text { Susunan Lapis } \\
\text { Perkerasan }\end{array}$ & $\begin{array}{c}\text { Desain Bina } \\
\text { Marga 2013 (Mm) }\end{array}$ & $\begin{array}{c}\text { Desain P2JN } \\
\text { Sulawesi-Selatan } \\
(\mathbf{M m})\end{array}$ & $\begin{array}{c}\text { Dipakai Di Lapangan } \\
(\mathbf{M m})\end{array}$ \\
\hline AC-WC & 40 & 40 & 40 \\
\hline AC-BC & 60 & 60 & 60 \\
\hline AC-Base & 80 & - & - \\
\hline LPA & 300 & 300 & 300 \\
\hline
\end{tabular}

\section{KESIMPULAN}

Berdasarkan hasil analisis yang telah dilakukan, maka diperoleh kesimpulan sebagai berikut.

Peningkatan jalan menggunakan perkerasan lentur dengan menggunakan metode Manual Desain Perkerasan 2013 diperoleh tebal lapis permukaan $A C$ - $W C$ setebal $40 \mathrm{~mm}$, lapis $A C-B C$ setebal $60 \mathrm{~mm}$ dan AC-Base setebal $80 \mathrm{~mm}$. Tebal lapis pondasi bawah LPA kelas A setebal $300 \mathrm{~mm}$.

\section{DAFTAR PUSTAKA}

[1] Undang-undang Republik Indonesia No. 38 Tahun 2004 Tentang Jalan, Jakarta: Direktorat Jendral Bina Marga.

[2] Departemen Pekerjaan Umum \& Direktorat Jenderal Bina Marga, 2013. Manual Desain Perkerasan Jalan Nomor 02/M/BM/2013. Jakarta: Bina Marga

[3] Kholiq, A., 2014. Perencanaan Tebal Perkerasan Lentur Jalan Raya Antara Bina Marga Dan Aashto'93 (Studi Kasus: Jalan Lingkar Utara Panyi Ngki Ran-Bari Bis Ajalengka). Jurnal J-Ensitec, Vol.1, No.1, hlm. 43-51.

[4] Pratama, Y., 2017. Peningkatan Jalan Dengan Menggunakan Perkerasan Lentur Ruas Jalan Beru-Cinandang Perkerasan Lentur Ruas Jalan Beru-Cinandang. Skripsi. Fakultas Teknik Sipil dan Perencanaan Institut Teknologi Sepuluh Nopember, Surabaya.

[6] Wibowo, J., 2017. Analisis Desain Perkerasan Jalan Metode Bina Marga 1987, Bina Marga 2002 dan Evaluasi Struktur Perkerasan Jalan (Ruas Pelebaran Jalan Bantal-Mukomuko Bengkulu). Skripsi. Program Studi Magister Teknik Sipil Sekolah Pascasarjana Universitas Muhammadiyah, Surakarta.

[5] Irianto, I., \& Warayaan, J. R., 2019. Perencanaan Tebal Perkerasan Lentur Dengan Metode Aashto 1993 Dan Mdp Jalan 2013 Pada Ruas Jalan Pirime-Balingga Kabupaten Lanny Jaya (Sta 0+ 000 S/D Sta 7+ 500). Jurnal Portal Sipil, Vol.8, No.2, hlm. 83-95. 
[7] Kurniawan, D., Yermadona, H., \& Wailussy, I, 2019. Perbandingan Tebal Perkerasan Lentur Metode Analisa Komponen Dan Aashto (Studi Kasus: Jalan Lubuk Alai-Koto Lamo Kabupaten Lima Puluh Kota). Rang Teknik Journal, Vol.2, No.2, hlm. 313 - 317.

[8] Ardiyana, R. R., \& Siswoyo, 2019. Perencanaan Tebal Perkerasan Lentur Dan Anggaran Biaya Di Jalan PareKediri Kota Kediri. Axial: Jurnal Rekayasa Dan Manajemen Konstruksi, Vol.7, No.2, hlm. 113-124.

[9] Wiemintoro, W., \& Wilis, G. R., 2020. Analisis Perencanaan Tebal Perkerasan Lentur Jalan dengan Menggunakan Metode Analisa Komponen Bina Marga 1987 Pada Ruas Jalan Banjaran-Balamoa. Skripsi. Fakultas Teknik Universitas Pancasakti Tegal, Tegal.

[10] Maryam, M., \& Putra, K. H., 2020. Analisis Perencanaan Tebal Perkerasan Lentur Dengan Metode Bina Marga (Studi Kasus: Jalan Luar Lingkar Timur Surabaya). Jurnal Teknologi dan Manajemen, Vol.1, No.2, hlm. $125-134$. 